\title{
The Mapping Mechanism of Modernization of National Governance and Corruption Governance
}

\author{
Xiong Lv \\ School of Public Management \\ Nanchang University \\ Nanchang, China 330031
}

\begin{abstract}
The corruption governance system is embedded in and mapped with the modernization of national governance. A full understanding and utilization of the mapping mechanism between them can improve the effectiveness of corruption governance, promote the construction of government integrity and stimulate the modernization of national governance. Therefore, in order to satisfactorily implement corruption governance and build government integrity from a perspective of modernization of national governance, it is significant for us to take into account the value, governing body, mechanism, achievements, risks, objectives of corruption governance before establishing a corruption governance system, to identify the mapping between the modernization of national governance and corruption governance system: $\mathrm{f}: \mathrm{C}-\mathrm{-}>\mathrm{M}$, and to clarify the mapping mechanism for avoiding misdirected mapping.
\end{abstract}

Keywords-words:modernization of national governance; corruption governance; mapping mechanism; governance path

\section{MOdEL OF THE MODERNIZATION OF NATIONAL GOVERNANCE}

\section{A. Positioning of the Modernization of National Governance}

The Decision of the Central Committee of the Communist Party of China on Deepening the Reform of Several Major Issues passed in the Third Plenary Session of the Eighth Central Committee of the Communist Party of China presents the concept of "Promoting the modernization of national governance and governance capability". Xi Jinping pointed out that national governance system is a system employed by the Communist Party to govern the state, comprising of the policies and principles, and laws and regulations of all fields, such as economic, political, cultural, social, ecological civilization and construction of the Communist Party. The modernization of national governance, interpreted as the fifth modernization, is a political reform package following "Four Modernizations". It is a driving force to help us achieve the objective of national governance - good governance, as well as a key for advancing the modernization of socialism with Chinese characteristics. The focuses of the modernization of national governance are the modernization of national governance system and governance capability. It incorporates the limitations of power and effectiveness of governmental functions in nature. The limitations of power refer to that the power can be alienated to its minimum level under the multi-level governance; while the effectiveness of governmental functions can be obtained by maximizing the effectiveness of power, resulting in "due rights $=$ received rights = legal rights". The modernization of national governance indicates that the concept of national governance has been strategically developed and its governance model is explanatory, enforceable and collaborative.

\section{B. Model of the Modernization of National Governance}

The objective of modernization of national governance is to achieve good governance which is characterized by democracy, extensive public services and outstanding achievements in political affairs by applying the rule of law to establish a transparent and accountable government system for ensuring the public opinion can be expressed and implemented, and the public rights can be exercised. The focuses of the modernization of national governance is to create a "four- dimensional-and-nine-sides model" "Fig.1", Four dimensions mean why to conduct governance, who is responsible for conducting governance, how to conduct the governance, namely, " $2 \mathrm{~W} 2 \mathrm{H}$ ", standing respectively for governance value / objective, governing body, governance mechanism, governance achievement/risk. Nine sides mean multi-dimensional governance value, good governance, multi-level governing body, strategic governance concept, collaborative mechanism, democratically-allocated rights, legalization of exercising public rights, optimal governance achievements and minimized risks. The key of ensuring the effectiveness of modernization of national governance is to establish and consolidate the four-dimensional-and-ninesides model. The governance value serves as the foundation of the modernization of national governance, and the governance objective (good governance) is described as the blue print of the modernization of national governance, governing body, governance concept/mechanism, governance achievement/risk are coordinates of the modernization of national governance. Corruption governance is an important part of the modernization of national governance and its framework is encompassed with the modernization of national governance [4]. As a consequence, the driving force of establishing a fourdimensional-and-nine-sides model is indirectly transformed

Chinese Library Classification Number: D26. 
into the endogenous force for establishing government integrity and fighting against the corruption activities, resulting in positive coupling between corruption governance and the modernization of national governance.

Coupling is established when two or more system or patterns of movement are closely associated by interaction

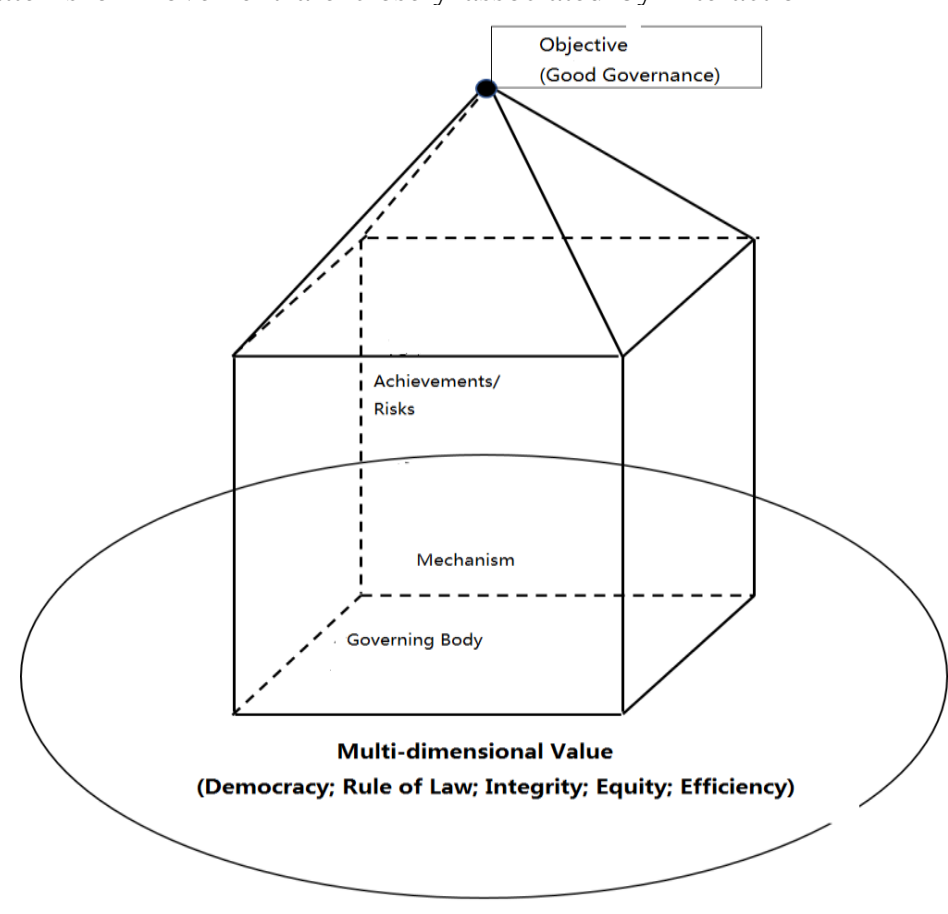

Fig. 1. Model of Modernization of National Governance - Original.

\section{ESTABLISHING OF CORRUPTION GOVERNANCE SYSTEM}

Guo Yong proposed the building up of government integrity system for a country based on the public awareness and social value. The Transparency International metaphorically referred government integrity system to as a temple [5]; Ni Xing and Xu Weiwei raised that a government integrity system with Chinese characteristics may incorporate the value, structure, mechanism, strategy and assessment [6]. He Zengke created the governance integrity policy and system framework for modern China and developed the criteria for evaluating the effectiveness of governance integrity for a country based on the basic principles of the modern national integrity system for a modern country [7].

The above scholars proposed the "Government Integrity Construction and Corruption Governance System" with different characteristics at macro, medium and micro levels. This paper divides the corruption governance structure into target layer, central layer and function layer at macro level from the aspect of modernization of national governance. As the foundation of corruption governance system, the function layer is the power source and the starting point of corruption governance with equity and good governance as its core, representing the effectiveness of governance with multidimensional value [8]. The central layer is the core of the whole corruption governance system with three basic with each other. It represents a dynamic relationship by which such systems are interdependent on each other, collaborative, and mutually simulative via positive interaction.

\begin{tabular}{|c|c|}
\hline \multicolumn{2}{|c|}{ Four-dimensions-and-nine-sides Model } \\
\hline Four Dimensions & Nine Sides \\
\hline \multirow[b]{2}{*}{$\begin{array}{l}\text { Value/objective } \\
\text { (why to conduct }\end{array}$} & Multi-dimensional value \\
\hline & Objective - good governance \\
\hline \multirow{2}{*}{$\begin{array}{c}\text { governance } \\
\text { Governing body } \\
\text { (Who is responsible } \\
\text { for governance) }\end{array}$} & Strategic governance concept \\
\hline & Multi-level governing body \\
\hline \multirow{3}{*}{$\begin{array}{l}\text { Mechanism } \\
\text { (How to conduct } \\
\text { governance) }\end{array}$} & Coordinated mechanism \\
\hline & Democratic right allocation \\
\hline & $\begin{array}{l}\text { Legalization of exercising } \\
\text { public rights }\end{array}$ \\
\hline \multirow{2}{*}{$\begin{array}{l}\text { Achievements/risks } \\
\text { (How is the } \\
\text { governance) }\end{array}$} & \\
\hline & $\begin{array}{l}\text { Optimal achievements } \\
\text { Minimized risks }\end{array}$ \\
\hline
\end{tabular}

coordinates, such as anti-corruption governing body, governance mechanism, and governance achievements/risk, which can project the central space of corruption governance (visualized as a cube to visually display that three coordinates are equally important and the central layer is symmetric and converged). The governing body for anti-corruption activities encompasses the state, society and market. The corruption governance mechanism comprises the normalized policy, legalized methods, various measurements, multi-level types, and integrated procedures for corruption governance; the achievements in corruption governance can be seen from the changes of number of corruption cases and corruption perception index. The changes in the number of corruption cases depend on the anti-corruption efforts, number of decreased corruption cases, accumulated corruption activities, change of corruption response time, suppressing of an increase in corruption cases, number of hidden corruption activities and so on. Corruption perception index concerns the corruption perception, corruption tolerance, degree of citizens' satisfaction with anti-corruption, level of involvement in anticorruption and so on. Corruption governance risks can be assessed with corruption repetition risk, possibility of collective corruption and anti-corruption failure costs and so on. The central layer is the core of the corruption governance system, fed with the power by the function layer and feeds the action results back to the target layer. The target layer is the objective of the corruption governance. A pyramid used to 
visually embody the target layer with the anti-corruption achievements converging to a single point at the top of target layer, that is the objective of good governance - effective and account government [9]. The target layer is the ultimate goal of corruption governance, located above the central layer. The positive and dynamic interaction of function layer, central layer and target layer can significantly increase corruption cost, reduce corruption incentives and consolidate the corrupt management space. Corruption Governance System "Fig. 2".

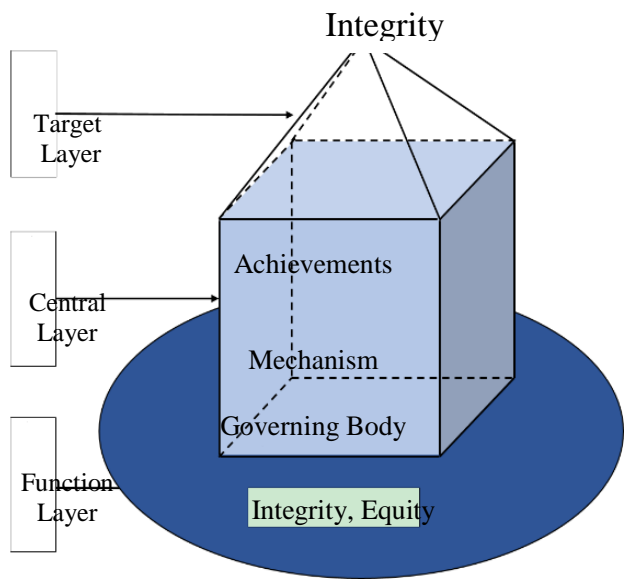

Fig. 2. Schematic Diagram of Corruption Governance - Original

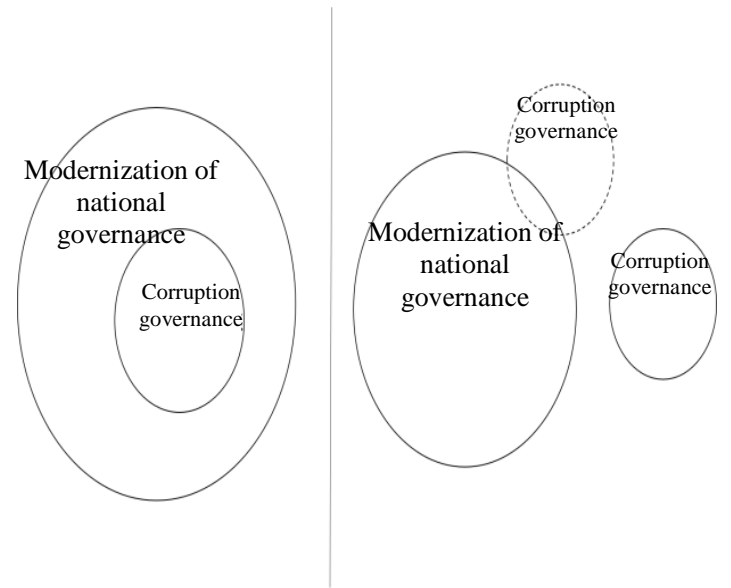

Fig. 3. Embedded Relationship and "Beyond" or Isolated Status - Original.

\section{MAPPING MECHANISM BETWEEN MODERNIZATION OF NATIONAL GOVERNANCE AND CORRUPTION GOVERNANCE}

\section{A. Precondition for the Rational Mapping - Embedded Relationship}

The mapping between the modernization of national governance and the corruption governance roots in the embedded relationship between them. In other words, the corruption governance system is encompassed by the modernization of national governance and serves as an important part of the modernization of national governance. The corruption governance embodies the objective of the modernization of national governance - good governance / government integrity, and allocates rationally the power, a core element of national governance system. It is objectively necessary for promoting the construction of national governance capacity and establishing the framework of national governance. An ineffective governance encourages the corruption activities, and thus, to promote the dynamic interaction and mutual dependence between the modernization of national governance and corruption governance system can help significantly eradicate soft power, resources Imbalance and economic inefficiency, and corruption subculture. Once going beyond or being divorced from the modernization of national governance, the anti-corruption activities will lose its political foundation and disassociate itself from the modernization of national governance "Fig. 3".

\section{B. Mapping Mechanism}

The corruption governance system is embedded into the modernization system of national governance and dynamically interrelated through mapping. A mirroring space is proposed to visually and easily analyze the mapping mechanism between the modernization of national governance and corruption governance system, which helps us to separate the corruption governance system from the modernization of national governance without changing the embedded relationship between them "Fig. 4".

We can use the formula $\mathrm{f}: \mathrm{C}$---> $\mathrm{M}$ to describe the mapping relationship between the modernization of national governance (Modernization) and corruption governance system (Corruption), wherein, $\mathrm{f}$ for mapping function, $\mathrm{C}$ for corruption governance system and $\mathrm{M}$ for modernization of national governance. The basic elements of corruption governance system are mapped to some of elements of the modernization of national governance, such as corruption governance value (equity) --> national governance value (rule of law, equity), anti-corruption governing body (the state) --> national governance body (the state, society and market), anticorruption objective (government integrity) --> objective of national governance (good governance). F-mapping function is embodied in the similarity of the macro architecture, the compatibility of the value system, the coupling of the governing body, the mechanism and the effect of national governance, and the consistency of the target between these two systems. 


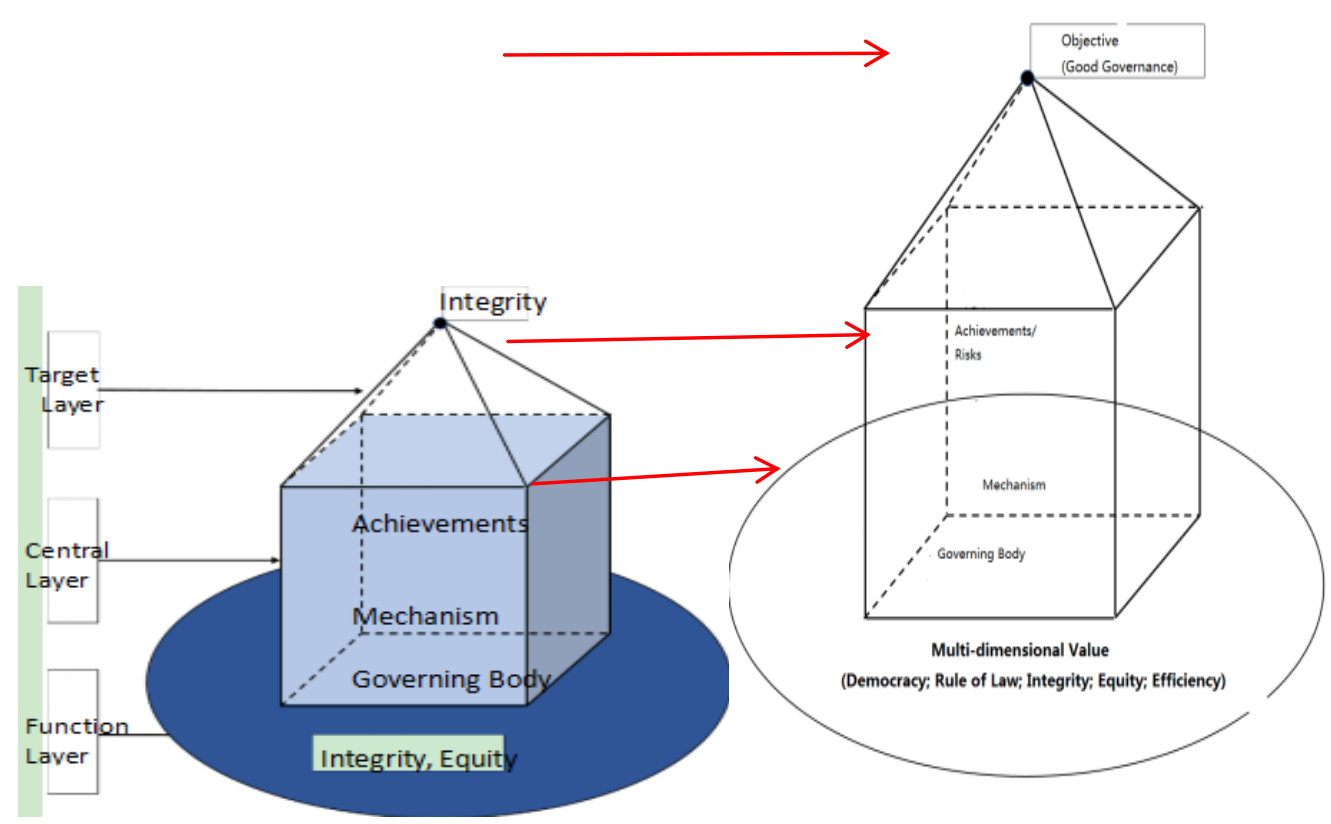

\begin{tabular}{|c|c|}
\hline Four Dimensions & Nine Sides \\
\hline \multirow{2}{*}{$\begin{array}{l}\text { Value/objective } \\
\text { (why to conduct } \\
\text { governance }\end{array}$} & Multi-dimensional value \\
\hline & Objective - good governance \\
\hline \multirow{2}{*}{$\begin{array}{l}\text { Governing body } \\
\text { (Who is responsible } \\
\text { for governance) }\end{array}$} & Strategic governance concept \\
\hline & Multi-level governing body \\
\hline \multirow{3}{*}{$\begin{array}{l}\text { Mechanism } \\
\text { (How to conduct } \\
\text { governance) }\end{array}$} & Coordinated mechanism \\
\hline & Democratic right allocation \\
\hline & $\begin{array}{l}\text { Legalization of exercising } \\
\text { public rights }\end{array}$ \\
\hline \multirow{2}{*}{$\begin{array}{l}\text { Achievements/risks } \\
\text { (How is the } \\
\text { governance) }\end{array}$} & Optimal achievements \\
\hline & Minimized risks \\
\hline
\end{tabular}

Fig. 4. Primary Image and Mirrored Image of the Modernization of National Governance - Original

Firstly, the similarity of the macro architecture. The corruption governance system, consisting of target layer, central layer and function layer, is highly similar to the modernization of national governance which incorporates multi-value system, governance mechanism system and objective system. If we consider the modernization of national governance as a parent company, the corruption governance system is a subsidiary of the parent company. The corruption governance is an important component of the modernization of national governance covering a wide and all-round scope. If the modernization is metaphorically referred to as a human body, the corruption governance system is an organ of the body. The relationship defined as "parent company and subsidiary" and "body and organ" represents the similarities and differences between the modernization of national governance and the corruption governance system.

Secondly, the compatibility of value systems. The modernization of national governance is a multidimensional and independent system, focusing on the core value of socialism and incorporating integrity, democracy, and rule of law at political level [10]; efficiency, equity, and public benefit at economic level; and cultivation, harmony and order at society level; while the core value of corruption governance system lies on the integrity and equity, which is components of value system of the modernization of national governance.

Thirdly, coupling of governing body, mechanism and achievement. The governing bodies of both the modernization of national governance and corruption governance integrate the state, society and market. The governance with multi-subjects involved transforms the state into the helmsman rather than the oarsman, and helps significantly remove and correct the problems (government failure, market failure and abuse of democratic system) and corruption activities (deformed national will - worship of officials, distorted social value worship of money and extravagance, public credibility crisis -
Tacitus Trap) in the governance arising from making a single subject to be responsible for governance. Despite of the healthy governance capacity and well-established governance system, insufficient coupling of governance mechanism will definitely cause a constantly decreasing margin benefits from governance, imbalanced power allocation, intensified sensitive information asymmetry, hindered construction of corruption governance system, dispersive governance capacity and increased anti-corruption cost. The achievements of anticorruption can embody the achievements of the modernization of national governance, as a consequence, effective anticorruption issue management can indicate that national governance works very well. Additionally, as the risks of corruption governance is logically and closely related to the modernization of national governance, the ineffective risk control of government integrity may lead to ineffective national governance.

Fourthly, the consistency of target. National governance is a game between power and right and corruption is a imbalance between the power and the right. As the modernization of national governance necessarily requires the reciprocity of power and responsibility, while the ultimate objective of corruption governance is to achieve governance integrity, an indicator of good governance, from political perspective, consequently, the corruption governance is consistent with the modernization of national governance based on their targets.

Fifthly, uniformity of energy conduction. Internal and external power sources are available for whether corruption governance or national governance. The internal power, originated from value layer (the function layer of corruption governance system and value layer of the modernization of national governance), is transferred from bottom to top. When arriving at the target layer, it will examine the gap between the intended objective and the actually-achieved objective and then feed the result back to function layer or value layer, 
playing a role of recycling and supply. We thus consider the corruption governance is consistent with the national governance based on the energy conduction.

\section{Mapping Failure}

1) Misdirected value dimension, and incompatible value systems - misunderstanding of corruption

The failure in the mapping of corruption governance system and the modernization of national governance can be seen from the incompatible value systems where the value of corruption governance conflicts with the value of the modernization of national governance, and especially the corruption and anti-corruption are misunderstood. Such misinterpretations contain: for example, some people believe that corruption is the lubricant of economy development; the public may be disappointed about the government when more corruption activities occur even though the government fights against them; the democracy system with three powers separated is the best medicine to cure corruption; moral corruption can not be grouped in the corruption; anticorruption activities is carried out temporarily, which is considered to make a great fuss about nothing since government uses excessive efforts to fight against corruption activities, etc.. The reason why such misinterpretations occur is that the value of corruption governance is wrongly positioned and assessed beyond the perspective of the modernization of national governance. Compared to its positive motivating role, corruption always has far more negative effect on an unrelated party (negative externality). A cognitive bias between the pros and cons is an indicator to assess the degree of mutual exclusion between the value of modernization of the national governance and that of the corruption governance. Consequently, the core value of national governance can determine the anti-corruption awareness and orientation, and is essential for establishing of government integrity.

2) Incomplete mapping, a single governing body, state solely responsible for governance - splitting of three governing bodies

A well-functioned governance system is achieved through the cooperation among three governing bodies, including the state, society and market [11]. In case of incomplete mapping and splitting of three governing bodies, powers and responsibilities of the state, market and society will inevitably overlap, resulting in a phenomenon where only the state is responsible for national affairs governance without receiving any supervision from the market and society, and whereby corruption grows sharply. For example, integration of enterprise management in government functions, excessive expansion of governmental power, weakened functions of market and society, intensified crisis of public credibility, and serious social conflicts, among which, planned economy is a typical example.

3) Rigid mapping, insufficient coupling of governance mechanism, and improperly converged or incorporated system - conducive to corruption

As the adhesive that binds the corruption governance system and the modernization of national governance together, the relational mapping, which is rigid and faint, may make it difficult to obtain a complete and strong coupling between the corruption governance and modernization of national governance in the governance mechanism, and then the coupling gap is adversely transformed into a space for corruption growth. We may find that the conflict between interest groups of the new policy and the old one arising from improper convergence of the old and new system brings the second best system, limiting the possibility of Pareto optima. For example, subjective understanding of Chinese corruption features; blind advocating of copying corruption governance model from foreign countries, that is maintaining the government integrity through paying officials high salaries; regulations are formulated and system is set up blindly without considering the structural imbalance in policy, resulting in institutional surplus; the role of rule of law in anti-corruption is underestimated, resulting in anti-corruption under rule of man and passive anti-corruption; the current anti-corruption is punishment-oriented.

4) Closed mapping loss, low-efficiency assessment of governance achievement, and risk control failure - defects of corruption monitoring system

The closed mapping loss refers to discontinued mapping due to asymmetric information and incompatible stimulus, that is the ending point of mapping (modernization of national governance) fails to response the starting point of mapping (corruption governance system), causing a vicious cycle of corruption governance with low-efficiency anti-corruption achievements assessment, ineffective control of risk in maintaining government integrity - improper corruption governance strategy, wrong political amendment, misunderstanding of policy, faint executive power - lowefficiency anti-corruption achievements assessment, ineffective control of risk in maintaining government integrity. One of the methods to break such vicious cycle is to improve the corruption monitoring system, to eliminate the limitations due to asymmetric information and incompatible stimulus, to close the mapping path, and to ensure complete and closed mapping, and thereby obtaining accurate and reliable governance achievement assessment, real-time and effective risk control of maintaining government integrity, and enhanced flow of energy of corruption governance.

5) Non-unique mapping, target replacement - disorder conduction of governance energy

We use the formula $\mathrm{f}: \mathrm{C}--->\mathrm{M}$ to describe the mapping relationship between the modernization of national governance and corruption governance system as mentioned above. If the mapping is not unique, target of corruption governance will be displaced easily, for example, response perfunctorily to policy, policy distortions, policy misunderstanding, additional policy, and policy selection. Target replacement occurs frequently to local government serving as an agency to exercise public powers, which can be interpreted with the internal mechanism for corruption actions: motivate + opportunity -> corruption[12], and caused subjectively by the local government due to its lack in rationality and self-interest motivation. The flexible space for implementing anticorruption policy (policy implementation at the local government's own discretion) facilities the occurrence of target displacement, and the displaced target thereby prevents 
the energy from conduction. The disorder or blocked anticorruption energy transmission will actually worsen the corruption, resulting in power allocation imbalance, waste of policy resource, overlapped governmental functions, divorce between powers and responsibilities, low-level coordination among all governmental authorities for fighting against all anti-corruption, insufficient institutional deterrent to corruption, and emerging opportunism.

\section{CORRuption Government Path In The PERSPECTIVE OF MAPPING}

\section{A. Follow the Value, Enhance the Function Layer and Activate the Power for Corruption Governance}

As the core value of national governance, democracy, rule of law, and fairness are also the orientation and standing point of corruption governance. To enhance the function layer, it is necessary to activate the power for corruption governance and thereby to strengthen the energy transmission to the central layer by advocating democracy, practicing the rule of law, improving the fairness, and increasing the effectiveness. In this way, the central layer can be successfully built up and a governance pattern dominant by one entity with multiple entities involved will be consolidated. Institutional surplus will be eliminated in an effective manner, and defective portions of system will be corrected in order to achieve institutional justice and structural balance. The power allocation and control mechanism for exercising powers will be further improved to ensure the powers can be exercised under the rule of law. Performance assessment system will be optimized at all aspects to guarantee fairness and effectiveness.

\section{B. Consolidate the Pattern with Three Governing Bodies, and Converge the Powers for Corruption Governance - Complete Mapping between Governing Bodies}

The pattern with three governing bodies, the state, society and market, can help create a power supervision net and converge the powers for corruption governance. Firstly, such pattern should be enhanced to allow three governing bodies to coexist without mutual intervention. The state should identify the relationship between power and responsibility, restraint the governmental behavior, intervene in the market, establish accountable and responsive government, and promote the effectiveness of governmental management; the market should clarify its power boundary, and eliminate the corruption space. The society should improve the public's awareness of the democracy and rule of law, supervise the corruption actions in rational manner, and properly participate in the anti-corruption. Secondly, to ensure three governing bodies can mutually response to each other, and to create a strongly interactive net. The frequent interaction among the state, market and society can not only help reduce information asymmetry, reconcile the intergovernmental relation, and public-and-government relation to prevent the public credibility crisis, falling into the Tacitus Trap, but also facilitate the state in obtaining social supervision information in real time and then to identify the points where corruption occurs easily and to punish corruption actions in short time.

\section{Innovate the Long-acting Anti-corruption System, Achieve the Modernization of System, and Narrow the Corruption Space - Sufficient Coupling}

The primary reason why corruption space exists is that the structural disorder is found in the corruption governance [13]. To narrow the corruption space, it is essential for us to establish a government integrity net and achieve modernized system. Since no long-acting anti-corruption mechanism is created to strategically monitor corruption action, and government integrity net is improperly established, the corruption governance system is wrongly transplanted and improperly converged, making it difficult for the anticorruption mechanism to work well. For this reason, we should practice the anti-corruption concept at all times. Firstly, to formulate the laws to regulating the punishments for corruption, to rely on the system deterrent force, to regulate the exercise of powers, to purify the political ecology, and to achieve the intended objective where officials are not dare to be corrupt. Secondly, to create a government integrity system net, to develop relevant supporting system, to avoid conflicts of interests, to eliminate corruption opportunism, to dispel corruption motives, and to prevent corruption at its source, and to achieve the objective relying on the system that no officials dare to be corrupt. Thirdly, to further promote integrity culture education, to create a healthy social environment, and to achieve the ultimate objective that everyone worships integrity and official do not want to be corrupt.

\section{Optimize the Corruption Measurement System, and Identify and Control Risks of Government Integrity Rapidly - Closed Mapping Path}

A complete and accurate corruption measurement system is a prerequisite for us to rapidly identify and precisely control the risk of government integrity. A closed mapping between the modernization of national governance and corruption governance system can be obtained when the logical cycle of corruption measurement system (establishing - trial operation complete - apply - optimize - consolidate - re-apply) is characterized by cooperativity, reproducibility and plasticity. The corruption measurement system can be optimized as below. Firstly, to get the corruption measurement, governing body, and governance mechanism to work together for better results based on two coordinates of corruption governance system (governing body and governance mechanism) and thereby to display the cooperativity of corruption measurement system to its maximum. Secondly, to display the reproducibility of corruption measurement system by eliminating the limitations due to asymmetric information and incompatible stimulus. Thirdly, to presenting its plasticity by connecting the function layer with the target layer of corruption governance system, and significantly promoting energy flow. A complete and optimal corruption measurement system can ensure that the mapping path is closed, effectively avoiding low-efficiency assessment of governance achievement, and failure in controlling the risk of government integrity. 


\section{E. Promote the Construction of Communist Party's Style and Government Integrity, Guide the Goal Regression and Ensure Orderly Energy Transmission - Single Mapping}

To further promote the construction of Communist Party's style and government integrity is a critical measure to reduce target replacement rate and to ensure successful energy conduction for corruption governance system. Firstly, to further promote the "Three Stricts and Three Honests" education campaign, to enhance "four awareness", and to implement "two responsibilities", to regulate harmful four practices, to improve of officials morale, and to build up an accountable government. Secondly, to take punishments and prevention measures together, to conduct patrol inspection, to introduce anti-corruption pioneer, to exert great efforts to fight against corruption actions, to ensure the political instructions flow effectively, to guide goal regression, to save political resources and to reduce governance cost. Thirdly, to transform the governmental functions, to establish good intergovernmental relation and government-and-the public relation, to prevent officials from pursuing the interests or being involved in power trading.

\section{CONCLUSION}

The mapping mechanism between corruption governance system and the modernization of national governance requires that a well-functioned corruption governance system needs to be rooted in the construction of the modernization of national governance. Whether the corruption governance system is modernized can be a key indicator for the effectiveness of modernization of national governance. The government integrity is a signal of good governance. The value, governing body, mechanism, achievements, risks, and objective of corruption governance dynamically converge together to create a compound system, and the effectiveness of such system is strongly associated with the modernization of national governance. As a consequence, we should integrate all powers to proceed with the corruption governance in the perspective of the modernization of national governance, and accurately comprehend the mapping mechanism between the modernization of national governance and corruption governance system. We should adhere to the function layer, strengthen the central layer and carry out anti-corruption activities according to the law in order to promote the overall establishing of modernization of corruption governance, to maintain the ecology of accountable government, and to achieve the government integrity.

\section{REFERENCES}

[1] Xi Jinping. The Decision of the Central Committee of the Communist Party of China on Deepening the Reform of Several Major Issues [N]. People's Daily

[2] Xi Jinping. Practical Alignment of the Thought with the Spirit of the Third Plenary Session of the Eighth Central Committee [N]. 2014-01-01.

[3] Wan Gaolong, Luo Zhijian. Power under the Perspective of the Rule of Law [J]. Truth Seeking. 2010(12): 74-79.

[4] Xu Guifang. Establishing of the Modernization of Corruption Governance System in China [J]. 2017(1).

[5] Guo Yong. Research on Chinese Government Integrity System [M]. Beijing: China Fangzheng Press, 2007: 57-115.
[6] Ni Xing, Xu Weiwei. Theoretical Framework and Research Orientation of Government Integrity System with Chinese Characteristics [J]. Academic Research. 2015(08): 38-43

[7] He Zengke. Establishing of Modern Chinese Government Integrity System - Research on Effective Punishment and Prevention of Corruption Activities [J]. Marxism and Reality. 2009(03): 48-59.

[8] Wang Xipeng, Yang Hu. Modernization of Corruption Governance System with Chinese Characteristics - Inherent Logic and Practical Exploration [J]. 2014(4).

[9] He Zengke. Institutionalized Anti-corruption: Internal Requirements for Modernization of National Governance [N]. Procuratorate Daily, 201607-19(2).

[10] He Zengke. Dimension and Orientation of Modernization of National Governance [J]. People Forum. 2014(27): 44-48.

[11] Yang Jingyun, Yang Aiping. Institutional Surplus and System Shortage - Structural Defects on the Construction of Chinese Government Integrity - Chen Jingyun [J]. 2011(12).

[12] Ren Jianming, Du Zhizhou. Corruption and Anti-corruption: Theory, Model and Method [M]. Beijing: Tinghua University Press, 2009: 108172.

[13] Bai Weichun. Institutional Dilemma and Countermeasures of Chinese Anti-corruption System [J]. 2011(3). 